Recepción: 19 / 02 / 2017

Aceptación: 19/ 07 / 2017

Publicación: 31 / 10 / 2017

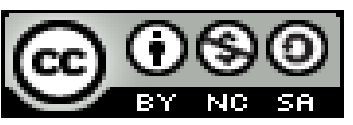

Ciencia de la salud

Artículo de investigación

\title{
Una mirada acerca de la estética dental
}

\section{A look at dental aesthetics}

\section{Um olhar sobre a estética dentária}

\author{
Juan A. Oliveira-del Rio ${ }^{\mathrm{I}}$ \\ juanoliveiradelrio@hotmail.com \\ Ivan A. Carrera-Bayas II \\ ivancarrera.12@gmail.com \\ Sandra Sandoval-Pedauga ${ }^{\text {III }}$ \\ sandra.sandoval@hotmail.com
}

Correspondencia: juanoliveiradelrio@hotmail.com

I Doctor en Ciencias Odontológicas, Universidad Laica "Eloy Alfaro” de Manabí, Manta, Ecuador.

II Odontólogo, Residente del Postgrado en Rehabilitación Oral, Universidad Central del Ecuador, Quito, Ecuador.

III Especialista en Rehabilitación Oral, Odontóloga, Universidad Laica "Eloy Alfaro" de Manabí, Manta, Ecuador. 


\title{
Resumen
}

La estética dental es muy importante porque, como su nombre lo sugiere, abarca todo aquello relacionado con la belleza, la estética o el embellecimiento de sus dientes, en sus muy distintas formas y posibilidades Las mejoras en los materiales dentales y en las técnicas para usar esos materiales, ha permitido a los odontólogos un medio adicional de expresión artística. Este trabajo revisa las modalidades de tratamiento para desarrollar una armonía dento facial total.

Palabras clave: principios estéticos; elementos estéticos; tratamiento odontológico.

\begin{abstract}
Dental aesthetics is very important because, as its name suggests, it covers everything related to beauty, aesthetics or the beautification of your teeth, in its very different forms and possibilities. Improvements in dental materials and techniques to use These materials have allowed dentists an additional means of artistic expression. This work reviews the treatment modalities to develop a total facial harmony.
\end{abstract}

Keywords: aesthetic principles; aesthetic elements; dental treatment.

\section{Resumo}

A estética dental é muito importante porque, como o nome sugere, abrange tudo relacionado à beleza, estética ou embelezamento de seus dentes, em suas formas e possibilidades muito diferentes. Melhorias em materiais e técnicas dentárias para usar Esses materiais permitiram aos dentistas um meio adicional de expressão artística. Este trabalho analisa as modalidades de tratamento para desenvolver uma harmonia facial total.

Palavras chave: princípios estéticos; elementos estéticos; tratamento odontológico.

\section{Introducción}

Desde civilizaciones antiguas, 3.700 años a.n.e., los egipcios practicaban prótesis dentales con sentido estético, que trataban de reponer las piezas perdidas. Se han descubierto momias con rasgos de haber recibido tratamientos dentales, como incrustaciones en los dientes utilizando oro, plata y diamantes, lo que constituía un signo de poder y belleza ${ }^{1}$. 
Esta tendencia continuó usándose en la antigüedad ya no solo por estética, sino como tratamiento para las afecciones bucales, de ahí que comenzaran a valorarse en este campo conceptos de belleza y estética dental como sinónimo de bienestar y salud bucal ${ }^{1}$.

Aunque la odontología ha evolucionado a través del tiempo, se mantiene su objetivo fundamental que es la rehabilitación del aparato masticatorio. En este sentido, el concepto de estética debe ser incorporando en la práctica diaria para obtener una restauración funcional que llene los requisitos estéticos del paciente y del odontólogo ${ }^{1}$.

El papel de la estética en el sector de la salud y en el nuestro específicamente, es fundamental. Tanto la forma del tratamiento como el trato que se le ofrezca al paciente, son elementos de gran importancia para lograr el bienestar biopsicosocial del individuo o de las poblaciones que tratamos ${ }^{1}$.

La estética facial y dental son factores importantes del atractivo físico. Sentirse insatisfecho con la apariencia física, puede tener repercusiones no solo estéticas, sino también sociales y psicológicas. Muchos pacientes están insatisfechos con su estética dental por el color de sus dientes $^{2}$.

Por lo que cada día es mayor el interés de los pacientes, en mejorar la apariencia de sus sonrisas y con ello lograr una mayor confianza en la comunicación con sus semejantes.

En nuestros días el tratamiento dental estético se facilita y a la vez se hace más exigido por la introducción de nuevos materiales y técnicas. La preocupación y responsabilidad del estomatólogo moderno incluye los recursos para mejorar el aspecto dental del paciente, lo cual fomenta el bienestar emocional y social del individuo ${ }^{3}$.

\section{Definición de estética dental}

La odontología estética o cosmética es una especialidad de la odontología, que soluciona problemas relacionados con la salud bucal y la armonía estética de la boca en su totalidad ${ }^{4}$.

Es evidente, que la estética es una especialidad de valor teórico o axiológico, siendo una rama de la filosofía que estudia los valores senso- riales, a veces llamados juicios del sentimiento o gusto. 
La estética se asocia muy de cerca a la filosofía de las Bellas Artes. La estética incluye el arte, así como el propósito que hay detrás 5 .

Así pues, la definición de estética dental estará sujeta a amplias variaciones en la interpretación personal y la percepción individual. Aunque el resultado final lo controla el odontólogo, el paciente debe contribuir con el proceso artístico de la toma de decisiones bajo la guía del odontólogo, a través de la presentación de todas las alternativas lógicas de tratamiento ${ }^{6}$.

Cabe destacar que, hoy en día el público en general se encuentra virtualmente saturado de información, a través de documentales en televisión, entrevistas en la radio y artículos en revistas relacionados a blanqueamientos, resinas compuestas, coronas, implantes, ortodoncia, cirugía ortognática, plástica y reconstructiva. La odontología estética está orientada, sin lugar a dudas, hacia nuevas fronteras de materiales y técnicas. Naturalmente, estas alternativas de tratamiento deben estar basadas en procedimientos restauradores y principios diagnósticos sólidos y reconocidos, que obligan al odontólogo a mantenerse informado y a educar al paciente. Los odontólogos que se mantienen informados, pueden esperar con gran confianza y entusiasmo a una de las épocas más interesantes de la profesión.

La planificación es fundamental en el éxito de todo tratamiento, sobre todo en la odontología estética, donde además de seleccionar los materiales a utilizar, debemos aplicar ciertos elementos artísticos a nuestro campo. El tratamiento se debe considerar un proceso creativo, donde tenemos la libertad de desarrollar día a día nuestras capacidades para lograr nuestras metas ${ }^{6}$.

\section{Tratamiento de estética dental}

Existen diferentes tratamientos de estética dental, para corregir los tres elementos que intervienen en la definición de la sonrisa perfecta: labios, encías y dientes.

El tratamiento de estética dental, incluye técnicas utilizadas para enderezar, blanquear y restaurar los dientes y darles nueva forma.

Los tratamientos estéticos tienden a lucir mejor y durar más en personas con dientes y encías saludables. De modo que deben tratarse caries dentales o enfermedades de las encías antes de comenzar con la odontología cosmética. 
En la actualidad existe una basta selección de materiales estéticos, con los que podemos ofrecerle al paciente una restauración: resinas, ionómeros de vidri, compómeros, cerómero, cerámica. ${ }^{7}$

\section{Alternativas estéticas en odontología restauradora}

Blanqueamiento: para mantener la eficacia y la seguridad del blanqueamiento, el odontólogo necesita educar al público acerca de las opciones de tratamiento. Inclusive, se debe insistir en la necesidad de consultar al odontólogo antes de comenzar un proceso de blanqueamiento en casa. Actualmente, el enfoque más efectivo para dientes manchados, es realizar un detallado estudio del caso para decidir si se utiliza el método en casa, en el consultorio o ambos, también se pueden combinar con otros tratamientos, como el de carillas. Este tipo de tratamiento tiene sus limitaciones y se deben discutir con el paciente. Heymann afirma que, basado en la experiencia clínica y de investigación actual, las técnicas de blanqueamiento de dientes vitales son seguras y efectivas, cuando usamos peróxido de carbamida al $10 \%$ por un período corto de tiempo y bajo la supervisión del odontólogo, sin ello no es recomendable ${ }^{6}$.

Carillas de cerámica: la odontología adhesiva, ha brindado grandes oportunidades a los odontólogos para lograr restauraciones estéticas, reducir la hipersensibilidad destinaria, preservar la estructura dental y crear sonrisas más placenteras. Actualmente, se ha logrado unión entre la porcelana y la estructura dental adecuada. El mejorar la calidad estética de este tipo de carillas, continúa siendo un reto para la odontología. Sin embargo, se han desarrollado nuevos materiales y técnicas para lograr restauraciones armoniosas. La expectativa de vida y la estética de esta restauración sobre pasa la de las restauraciones de resina ${ }^{6}$.

Las carillas de porcelana, son una alternativa estética a tener en cuenta por sus resultados clínicos a largo plazo y por la agresión mínima al tejido dentario.

Resinas compuestas: las resinas compuestas pueden ser la solución conservadora para resolver los problemas estéticos en nuestros pacientes. Los fabricantes han desarrollado sistemas sofisticados de resinas compuestas con múltiples colores, caracterizadores y opacadores que permiten al odontólogo, ofrecer restauraciones altamente estéticas ${ }^{6}$. 
Hoy en día, las resinas compuestas son el material restaurador más popular utilizado en odontología restauradora estética. Los materiales adhesivos se han utilizado durante muchos años y han demostrado una gran versatilidad, dentro de los materiales restauradores ${ }^{6}$.

Los resultados clínicos parecen indicar que el éxito se basa en una adecuada selección del caso. Christensen y Leinfelder afirman que las resinas compuestas directas, jugarán un papel importante como alternativa restauradora en el futuro ${ }^{6}$.

Enderezamiento de los dientes (tratamiento de ortodoncia): el tratamiento de ortodoncia es bastante lento, y por lo general tarda de uno a dos años, según la gravedad del problema. Existen diferentes tipos de aparatos ortodóncicos. Algunos se pueden quitar, mientras que otros se fijan en su sitio ${ }^{1}$.

Cirugía plástica de encía: la cirugía plástica de encía se encarga de corregir los diferentes problemas, que se pueden ocasionar en las encías. Los más comunes suelen ser los espacios entre dientes, la altura de las encías y la pigmentación ${ }^{6}$.

Implante: los implantes oseointegrados se han convertido en una opción de tratamiento para los pacientes edéntulos. Afortunadamente los implantes pueden ofrecer estabilidad y retención para prótesis semifijas. Con frecuencia si utilizan clips, aditamentos de precisión, barras, entre otros ${ }^{6}$.

El odontólogo debe de diseñar un tratamiento integral, en el cual cada especialidad oriente sus acciones al logro de la función y de una sonrisa placentera ${ }^{6}$.

Se realizó una investigación con la finalidad de valorar la repercusión psicosocial de las alteraciones estéticas faciales, de determinar el nivel de prioridad que ocupan los tratamientos estéticos dentales. Los resultados del trabajo demostraron que las afecciones estéticas dentales, tienen gran repercusión psicosocial, lo que unido al haber encontrado las lesiones traumáticas como las afecciones estéticas de mayor prevalencia, evidencio la necesidad de enfatizar la labor educativa en este aspecto ${ }^{6}$.

Así mismo Puebla Varas ${ }^{8}$ planteo en su estudio, que la autopercepción de estética dental se ve modificada positivamente en pacientes sometidos a blanqueamiento dental, al compararla previo 
al blanqueamiento y al término del blanqueamiento, así como también al compararla previo al blanqueamiento y al mes del blanqueamiento. No existen diferencias en la autopercepción de estética en pacientes sometidos a blanqueamiento dental, al comparar el término del blanqueamiento versus 1 mes posterior a éste.

Toledo Reyes ${ }^{9}$ demostró en su investigación, que el índice de estética (DAI) es efectivo en la identificación de necesidades de tratamiento prioritario y conveniente al compararlo con el criterio del especialista

De igual manera Serra Pérez ${ }^{10}$ pudo afirmar en su investigación, que el análisis de los 10 componentes o características oclusales que integran el IED, permitió definir la frecuencia de anomalías que condicionan la aparición de maloclusiones, donde el apiñamiento en los segmentos incisales, el espaciamiento y el diastema resultaron predominantes, y al mismo tiempo posibilitó comprobar la multicausalidad al establecer comparaciones con otros estudios. Igualmente se identificaron las necesidades de tratamiento ortodóncico y se concluyó que la mayoría de los adolescentes de la serie no lo necesitaban o solo requerían un tratamiento menor.

\section{Referencias Bibliográficas}

1- Otero Baxter Yulisa, Seguí Ulloa Alexander. Las afecciones estéticas: un problema para prevenir. Rev Cubana Estomatol 2001 [citado 2017 abril 10]; 38(2): 83-89. Disponible en: http://scielo.sld.cu/scielo.php?script=sci_arttext\&pid=S0034-75072001000200002\&lng=es

2- Inda Alamos D. Evaluación de la autopercepción de la estética dental e impacto psicosocial en pacientes sometidos a blanqueamiento dental, seguimiento de 9 meses. 2016. [citado 2017 abril 10] Disponible en: http://repositorio.uchile.cl/handle/2250/142444

3- Martínez P. El color en odontología y cómo resolver sus problemas. Rev ADM 1991; 48(1):36

4 Sacoto Navia M. Definición de la odontología estética o cosmética dental.2012, [citado 2017 abril 10] Disponible en: https://marianasacotonavia.com/2012/08/15/mariana-sacotonavia-ortodoncia-invisible-barcelonadefinicion-de-la-odontologia-estetica-o-estetica-dental/ 
5- Introducción a los conceptos de estética dental. 2014 [citado 2017 abril 10] Disponible en : media.axon.es/pdf/88901_2.pdf

6- González Blanco O, Solórzano Peláez A, Balda Zavarce R. Alternativas de tratamiento en odontología estética. Acta odontol. 1999 [citado 2017 abril 10]; 37 (3) Disponible en: http://www.scielo.org.ve/scielo.php?script=sci_arttext\&pid=S0001-63651999000300011

7- Adler D. La estética y la odontología moderna. 2013. [citado 2017 abril 10] Disponible en : http://www.odontologosecuador.com/espanol/artodontologos/estetica_y_odontologia_modern a.htm

8- Puebla Varas, O. Evaluación de la autopercepción de estética dental en pacientes sometidos a blanqueamiento dental. 2013. [citado 2017 abril 10] Disponible en: http://repositorio.uchile.cl/handle/2250/117511

9- Toledo Reyes Lilian, Machado Martínez Miriam, Martínez Herrada Yaumara, Muñoz Medina Mabel. Maloclusiones por el índice de estética dental (DAI) en la población menor de 19 años. Rev Cubana Estomatol. 2004 [citado 2017 abril 10]; 41(3). Disponible en: http://scielo.sld.cu/scielo.php?script=sci_arttext\&pid=S0034-75072004000300006\&lng=es

10- Serra Pérez L, Castañeda Deroncelé M, Ricardo Reyes M Berenguer Gouarnaluses M y Bibiana Comas Mirabent R. Índice de estética dental en adolescentes de una secundaria básica urbana. Rev medisan 2016, [citado 2017 abril 10]; 20(9). Disponible en: http://www.medisan.sld.cu/index.php/san/article/view/1054/html 